\title{
Use of the Ella Danis stent in severe esophageal bleeding caused by acute necrotizing esophagitis
}

A 45-year-old man presented with hematemesis, melena, and abdominal pain. Because he had clinical and laboratory signs of hypovolemic shock, the patient underwent an emergency gastroduodenoscopy. The findings of the endoscopy were: massive bleeding in the upper gastrointestinal tract, macroscopic necrosis, ulceration, and severe bloody oozing in the lower third of the esophagus. Because of the high risk of perforation, clipping and injection of epinephrine were contraindicated. We therefore proceeded to insert a coated Ella Danis stent (Ella-CS, Hradec Kralove, Czech Republic) as rescue management ( Fig. 1 a), and with this we achieved immediate hemostasis. The patient stabilized within 24 hours of admission and a repeat endoscopy showed hemostasis had been maintained ( Fig.1b). The stent was removed on day 4 after implantation, and the patient was discharged without experiencing any further complications.

Effective use of this stent in the rescue treatment of acute esophageal variceal bleeding has been reported in previous studies $[1,2]$. Currently, placement of this stent seems to be an attractive alternative treatment in refractory esophageal variceal bleeding, where band ligation cannot be performed. However, as yet data on efficacy, safety, and complications are not available [3].

With regards to the use of stents for the treatment of nonvariceal esophageal disorders, recent publications have already shown successful off-label use of the Ella Danis stent in patients with bleeding after endoscopic sphincterotomy and extensive esophageal mucosectomy, as well as in patients with staple line or anastomotic leakage, esophageal rupture, and bleeding from esophageal ulcers after successful endoscopic band ligation [3-5].

These recent publications do have several limitations and are not really comparable with regards to patients and methods. However, despite the lack of larger effica-

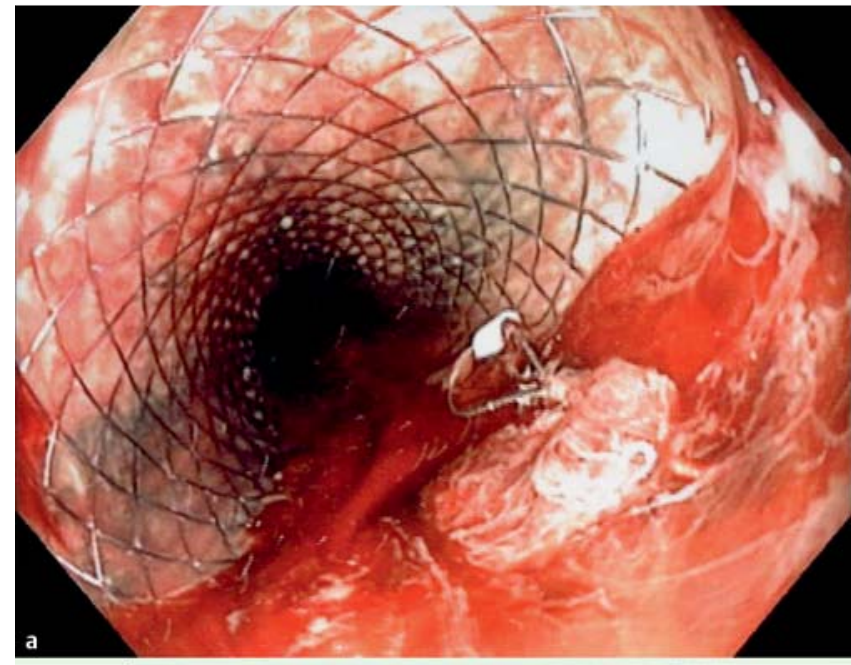

Fig. 1 Endoscopic views in a patient who had had bleeding due to acute necrotizing esophagitis showing: a the Ella Danis stent in situ; b continued hemostasis 1 day after stent implantation.

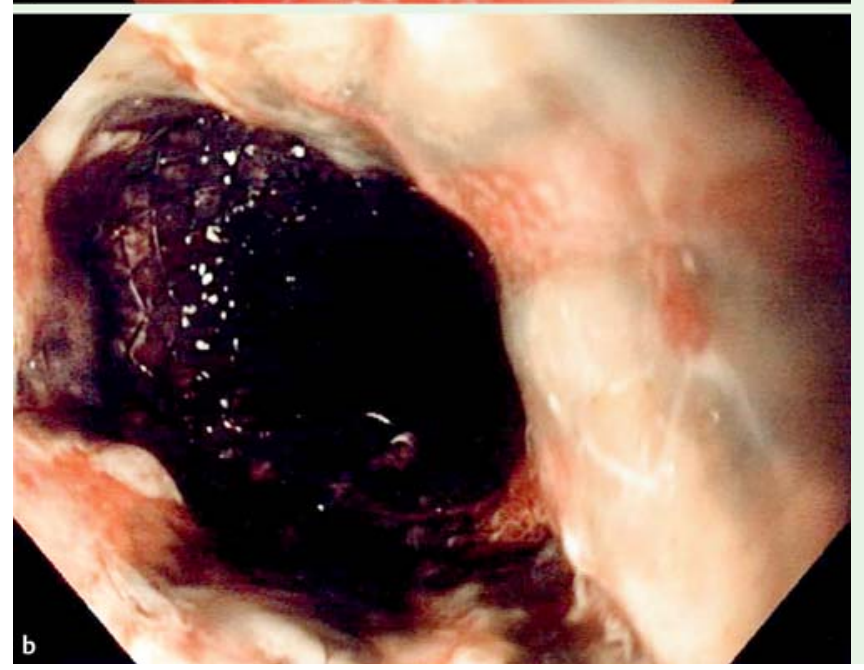

stent implantation.

cy studies, the implantation of an Ella Danis stent appears to be a promising alternative method, not only for refractory acute esophageal variceal bleeding, but also for patients with nonvariceal esophageal bleeding, if other methods have already failed or are not available in an emergency situation.

Endoscopy_UCTN_Code_TTT_1AO_2AD

Competing interests: None
Zora Messner ${ }^{1}$, Michael Gschwantler², Heinrich Resch ${ }^{1}$, Gerd Bodlaj ${ }^{1,3}$

1 Second Department of Medicine, St. Vincent Hospital, Vienna, Austria

2 Fourth Department of Internal Medicine, Wilhelminenspital, Vienna, Austria

${ }^{3}$ Department of Internal Medicine, Medical University of Graz, Graz, Austria 


\section{References}

1 Hubmann R, Bodlaj G, Czompo $M$ et al. The use of self-expanding metal stents to treat acute esophageal variceal bleeding. Endoscopy 2006; 38: 896-901

2 Wright G, Lewis H, Hogan B et al. A self-expanding metal stent for complicated variceal hemorrhage: experience at a single center. Gastrointest Endosc 2010; 71: 71 - 78

3 Wong Kee Song LM, Banerjee S, Barth BA et al. Emerging technologies for endoscopic hemostasis. Gastrointest Endosc 2012; 75 : 933-937
4 Babor R, Talbot M, Tyndal A. Treatment of upper gastrointestinal leaks with a removable, covered, self-expanding metallic stent. Surg Laparosc Endosc Percutan Tech 2009; 19: e1 - e4

5 Mishin I, Ghidirim G, Dolghii A et al. Implantation of self-expanding metal stent in the treatment of severe bleeding from esophageal ulcer after endoscopic band ligation. Dis Esophagus 2010; 23: E35-E38

\section{Bibliography}

DOI http://dx.doi.org/

10.1055/s-0034-1365384

Endoscopy 2014; 46: E225-E226

(c) Georg Thieme Verlag KG

Stuttgart · New York

ISSN 0013-726X

\section{Corresponding author}

\section{G. Bodlaj, MD}

Second Department of Medicine

St. Vincent Hospital Vienna

Stumpergasse 13

A-1060 Vienna

Austria

Fax: +43-1-599884043

gerd.bodlaj@bhs.at 